\title{
Comparison of different methods of postoperative analgesia after thoracotomy-a randomized controlled trial
}

\author{
Szymon Bialka ${ }^{1}$, Maja Copik ${ }^{1}$, Andrzej Daszkiewicz ${ }^{1}$, Eva Rivas ${ }^{2}$, Kurt Ruetzler $^{2}$, Lukasz Szarpak ${ }^{3,4}$, Hanna \\ Misiolek $^{1}$ \\ ${ }^{1}$ Department of Anaesthesiology and Critical Care, School of Medicine with Division of Dentistry in Zabrze, Medical University of Silesia, Zabrze, \\ Poland; ${ }^{2}$ Department of Outcomes Research, Cleveland Clinic, Cleveland, OH, USA; ${ }^{3}$ Faculty of Medicine, Lazarski University, Warsaw, Poland; \\ ${ }^{4}$ Department of Emergency Medicine, Warsaw Medical University, Warsaw, Poland \\ Contributions: (I) Conception and design: S Bialka, H Misiolek, M Copik; (II) Administrative support: H Misiolek, L Szarpak; (III) Provision of study \\ materials or patients: S Bialka, M Copik, A Daszkiewicz; (IV) Collection and assembly of data: All authors; (V) Data analysis and interpretation: \\ S Bialka, L Szarpak, K Ruetzler, H Misiolek; (VI) Manuscript writing: All authors; (VII) Final approval of manuscript: All authors. \\ Correspondence to: Lukasz Szarpak. Faculty of Medicine, Lazarski University, 43 Swieradowska Str., 02-662 Warsaw, Poland. Email: Lukasz.szarpak@gmail.com.
}

Background: Continuous thoracic epidural analgesia (TEA) is a preferred method of postoperative analgesia in thoracic surgery. Intravenous patient-controlled analgesia (IVPCA) may be an effective alternative. One of the most commonly used opioids in PCA is morphine. It has high antinociceptive efficacy but is associated with many adverse events. Oxycodone can be an alternative. A small number of scientific reports comparing morphine and oxycodone in PCA for the treatment of acute postoperative pain after thoracotomy was the reason to conduct this study.

Methods: Prospective, randomised, observational study. In total of 99 patients scheduled for elective thoracotomy were randomized into three study groups. TEA group received continuous TEA as a method of postoperative pain management, morphine (MF) group received morphine IVPCA, and morphine (OXY) group oxycodone IVPCA. For 48 hours' hemodynamic parameters, level of pain, sedation and the need for rescue analgesia were monitored. After 48 hours' patients were asked about their satisfaction with pain treatment using Likert scale and assessment of opioid related adverse events via overall benefit of analgesia score (OBAS).

Results: The level of pain in visual analogic score (VAS) and Prince Henry Hospital Pain Score (PHHPS) scales was significantly lower in TEA group with no significant difference between groups MF and OXY. Using morphine in PCA was associated with a significantly higher likelihood of need of rescue analgesia. The level of sedation in Ramsay scale was significantly higher in MF compared to OXY and TEA group. There were no significant differences between groups in OBAS scale. TEA group was characterized by the highest degree of patient satisfaction.

Conclusions: TEA provided superior anaesthesia compared to PCA in our study group. Use of PCA oxycodone in postoperative pain management after open thoracotomy provides similar nociception control compared to morphine but is associated with less sedation and patients using oxycodone IVPCA require smaller doses of rescue analgesia compared to systemic morphine IVPCA.

Keywords: Postoperative analgesia; thoracotomy; patient-controlled analgesia (PCA); oxycodone; morphine

Submitted Apr 22, 2018. Accepted for publication Jul 12, 2018.

doi: $10.21037 /$ jtd.2018.07.88

View this article at: http://dx.doi.org/10.21037/jtd.2018.07.88 


\section{Introduction}

About 75 million surgeries, including about 400,000 thoracic procedures are performed in the United States annually. Thoracic surgeries, including thoracotomy and video-assisted thoracic surgery (VATS) are some of the highest risk and most painful procedures. Skin incision, intraoperative tissue retraction and dissection, intravasal cannulations and drainages all contribute to intense pain after thoracic surgery. Treatment of acute post-surgical pain is essential but remains challenging. Poorly controlled acute pain after thoracic surgery affects quality of live after surgery and may contribute to postoperative complications (1-3). Despite improvements in aggressive perioperative analgesia, acute post-surgical pain frequently progresses to persistent post-surgical pain (4).

Thoracic epidural anesthesia remains the gold standard for treating acute pain after thoracic surgery (5-7). However, epidural anesthesia rarely produces devastating complications and cannot be used when patients are anticoagulated or patients is having severe spine deformities (8).

Whether administered intravenously, orally, or neuraxially, opioids are an important component of most treatment regimens following thoracic surgeries. Intravenous opioid patient-controlled analgesia (PCA) systems have been demonstrated to be safe in patients having thoracic surgery (9).

The most commonly used drug in intravenous PCA is morphine. It has a very good analgesic effect but it is also associated with a number of adverse effects, including respiratory depression, excessive sedation, nausea, vomiting, ileus and constipation (9-11). Alternatively, oxycodone is becoming increasingly popular, as analgesic potency is comparable to morphine, but was reported to cause less opioids related adverse events (12-15).

The optimal pain strategy after thoracic surgery is still controversially discussed. Therefore, the aim of this is to investigate the efficacy, in terms of acute postoperative pain relief, incidence of opioid-relate adverse events and patient satisfaction scores, of continuous thoracic epidural analgesia (TEA), intravenous oxycodone PCA and intravenous morphine PCA as acute postoperative treatment in adults having antero-lateral thoracotomy.

\section{Methods}

This is a randomized, observational study was conducted in Medical University of Silesia, Poland. With approval of the Institutional Review Board (KNW/0022/KB1/23/13) and after obtaining written informed consent, we enrolled 104 patients scheduled for elective anterolateral open thoracotomy between September 2013 to June 2014.

All patients were aged between 18 and 77 years, a body mass index between $19-30 \mathrm{~kg} / \mathrm{m}^{2}$, and had American Society of Anesthesiology (ASA) physical status between 1 and 3. Exclusion criteria were lack of consent, significant coagulopathy, contraindication to TEA or drugs used in protocol, history of chronic pain, chest wall neoplastic invasion, visible thoracic spine deformities, previous spine surgery, mental state preventing from effective use of PCA device.

\section{Protocol}

Patients were randomly assigned to one out of three groups (1:1:1):

* Thoracic epidural anesthesia (TEA);
- Intravenous morphine (MOR);
- Intravenous oxycodone (OXY).

Randomization without stratification was based on computer generated codes, which were kept in sequentially numbered opaque envelopes.

All patients were premedicated with up to $15 \mathrm{mg}$ midazolam orally. In patients assigned to the TEA group, the TEA at T3-T8 epidural space was placed by an experienced anesthesia attending. Standard monitoring including electrocardiogram, non-invasive blood pressure measurement and pulse oximetry was applied. General anesthesia was induced with a combination of propofol of approximately $2 \mathrm{mg} / \mathrm{kg}$, cisatracurium at approximately $0.15 \mathrm{mg} / \mathrm{kg}$, and fentanyl at approximately $2 \mu \mathrm{g} / \mathrm{kg}$. Additional doses were given as clinically indicated. Patients were intubated using a left-sided double lumen tube in adequate size. Patients were then positioned in lateral position. Anesthesia was maintained using sevoflurane. At the end of surgery, patients were quickly weaned from mechanical ventilation and extubated. As soon as the patients arrived in the postoperative care unit (PACU), the analgesic treatment was started as indicated by the randomization before surgery and lasted for the first 48 hours after end of surgery. Patients were thereafter given $1 \mathrm{~g}$ paracetamol intravenously on a 6-hour interval and $100 \mathrm{mg}$ ketoprofen on a 12-hour interval as a rescue medication, if necessary.

In patients assigned to the TEA group, a continuous epidural infusion consisting of $0.1 \%$ bupivacaine combined with $0.0006 \%$ fentanyl with a rate according to the modified 
Table 1 Patient demographic characteristics

\begin{tabular}{|c|c|c|c|c|}
\hline Variables & Thoracic epidural $(n=33)$ & Morphine PCA $(n=32)$ & Oxycodone PCA (n=34) & $P$ value \\
\hline Male/female (n) (\%) & $14[42] / 19[58]$ & $15[47] / 17[53]$ & $18[53] / 16[47]$ & 0.82 \\
\hline BMI $\left(\mathrm{kg} / \mathrm{m}^{2}\right)$ & $26.7 \pm 4.5$ & $24.6 \pm 3.9$ & $27.4 \pm 3.3$ & $<0.05$ \\
\hline ASA class, I/II/III (n) & $4 / 20 / 9$ & $4 / 17 / 11$ & $1 / 24 / 9$ & 0.49 \\
\hline
\end{tabular}

Data are expressed as: mean \pm SD or number of cases (percentage). BMI, body mass index; ASA, American Society of Anesthesiology; $\mathrm{SD}$, standard deviation; PCA, patient-controlled analgesia.

Bromage formula $(0.8 \mathrm{~mL} /$ hour $+0.05 \mathrm{~mL}$ for every $5 \mathrm{~cm}$ of height above $150 \mathrm{~cm}$ for every spinal segment) was started.

Patients assigned to the MOR group, received boluses of 1-2 $\mathrm{mg}$ of morphine until pain visual analogic score (VAS) was at a maximum of 3 in the PACU. Afterwards the demand dose was a $1-2 \mathrm{mg}$ bolus with a $5 \mathrm{~min}$ lockout, but no hourly limit. During the night, the basal rate was increased to 2-4 $\mathrm{mg}$ per hour.

Patients assigned to the OXY group, received boluses of $1 \mathrm{mg}$ of oxycodone until pain VAS score was at a maximum of 3 in the PACU. Afterwards the demand dose was a $1-2 \mathrm{mg}$ bolus with a $5 \mathrm{~min}$ lockout, but no hourly limit. During the night, the basal rate was increased to $2-4 \mathrm{mg}$ per hour.

\section{Measurements}

Demographic [age, sex, height, weight and body mass index $(\mathrm{BMI})$ and clinical data [comorbidities, arterial blood pressure and pain level at rest and movement by using VAS (16), and Prince Henry Hospital Pain Score (PHHPS) (17), respectively] were reordered before surgery.

Heart rate, non-invasive arterial blood pressure, pain intensity at rest [by using VAS (16) and PHHPS] sedation level with the Ramsay scale (18), and analgesic requirement were recorded at $0,1,2,4,8,12,18,24,30$, $36,42,48$ postoperative hours. We also registered total epidural, morphine and oxycodone infusion requirements, as well as opioid-related adverse events at 24 and 48 hours postoperatively by using opioid related side effects scale (ORSDS) (19-21) and overall patients' postoperative analgesia satisfaction with Likert scale (22).

\section{Statistical analysis}

Data were analyzed using Statistical 10.0 PL (StatSoft,
Tulusa, OK, USA) and MS Office Excel (Microsoft Inc., Redmond, WA, USA). Data were assessed for normality using the Shapiro-Wilk test. Normally distributed data were analyzed using Student's $t$-test for independent variables; nonparametric data were analyzed using the Mann-Whitney $U$ test. For categorical variables $\chi^{2}$ test with Yates correction were applied as appropriate. The variability of the parameters in time and between the groups was analyzed with parametric analysis of variance for multiple measurements (MANOVA) and post-hoc contrast analysis. Recursive weighted least squares estimation method was used for fitting a regression model of variability of studied data over time. $\mathrm{P}<0.05$ was considered statistically significant.

\section{Results}

During the study period, 110 patients underwent anterolateral thoracotomy and were screened for this study. Totally, 105 patients fulfilled inclusion and exclusion criteria's and were randomly assigned to the three study groups, resulting in 35 patients in each group.

Overall, six patients were excluded after randomization: 2 patients from TEA group due to significant hypotension and bradycardia during surgery, 3 from MOR due to over-sedation, gastro-intestinal bleeding and urgent rethoracotomy; and, 1 subject from OXY group failed to complete the study due to severe pain that could not be controlled by drugs allowed by the protocol.

Finally, ninety-nine patients (47 men and 52 female) with an age of $63 \pm 9$ years, and a BMI of $26 \pm 4 \mathrm{~kg} / \mathrm{m}^{2}$ completed the study. Demographics and main clinical findings are presented in Table 1. There were no significant differences between groups in age, gender, and ASA physical status. $\mathrm{BMI}$ was lower in MOR compared to patients assigned to 
Table 2 Systolic blood pressure in preselected time points

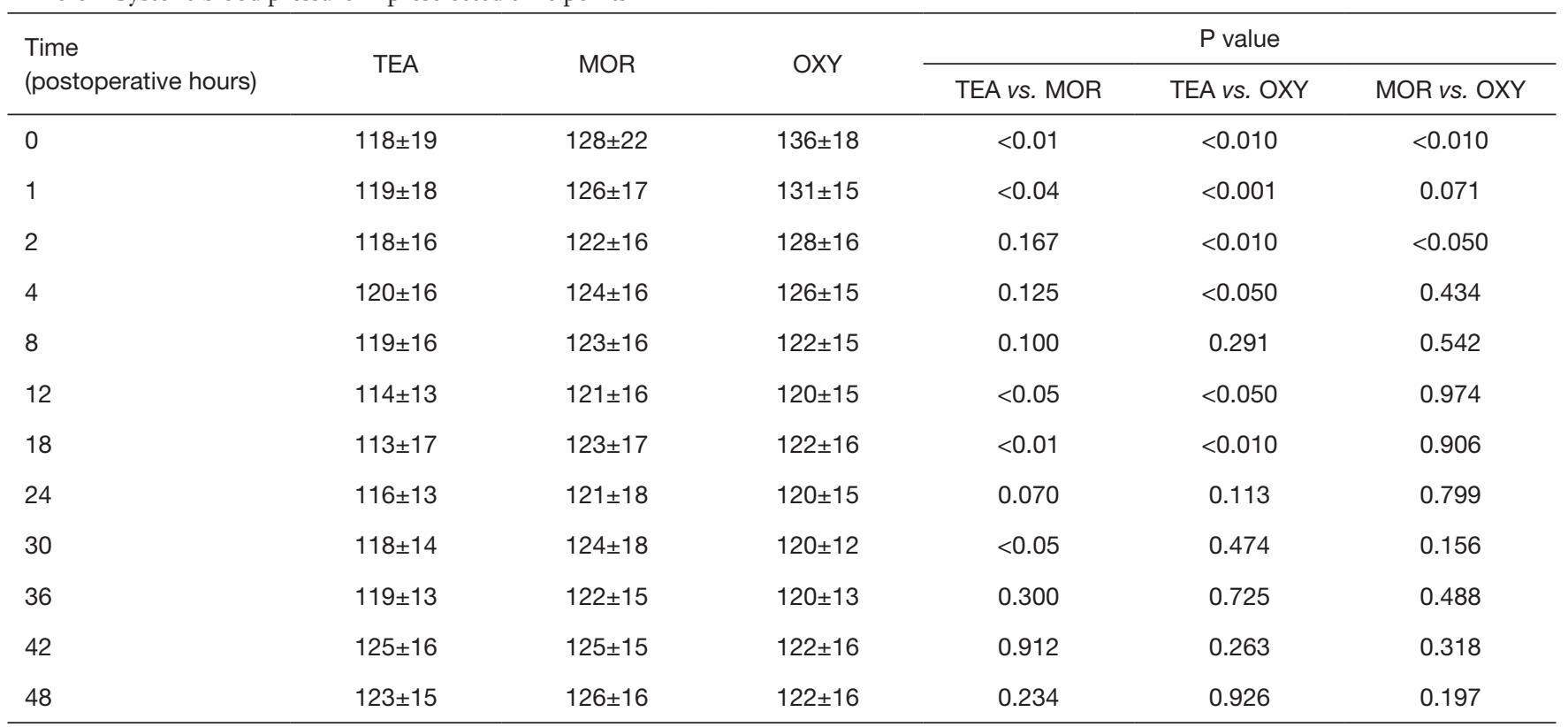

Data are expressed as: mean \pm SD. TEA, thoracic epidural analgesia; MOR, intravenous morphine PCA; OXY, intravenous oxycodone PCA; SD, standard deviation; PCA, patient-controlled analgesia.

Table 3 Pain intensity at rest by using VAS in preselected time points

\begin{tabular}{|c|c|c|c|c|c|c|}
\hline $\begin{array}{l}\text { Time } \\
\text { (postoperative hours) }\end{array}$ & TEA & MOR & OXY & \multicolumn{3}{|c|}{$P$ value } \\
\hline 0 & $2 \pm 2$ & $4 \pm 2$ & $4 \pm 2$ & $<0.001$ & $<0.001$ & $<0.050$ \\
\hline 1 & $2 \pm 2$ & $4 \pm 2$ & $4 \pm 2$ & $<0.001$ & $<0.001$ & 0.867 \\
\hline 2 & $2 \pm 2$ & $4 \pm 1$ & $4 \pm 2$ & $<0.001$ & $<0.001$ & 0.430 \\
\hline 8 & $2 \pm 2$ & $3 \pm 1$ & $3 \pm 2$ & $<0.001$ & $<0.001$ & 0.812 \\
\hline 12 & $2 \pm 2$ & $3 \pm 1$ & $3 \pm 2$ & $<0.001$ & $<0.001$ & 0.422 \\
\hline 18 & $2 \pm 2$ & $3 \pm 1$ & $3 \pm 1$ & $<0.001$ & $<0.001$ & 0.503 \\
\hline 24 & $2 \pm 2$ & $3 \pm 1$ & $3 \pm 2$ & $<0.001$ & $<0.001$ & 0.494 \\
\hline 42 & $1 \pm 1$ & $2 \pm 1$ & $2 \pm 1$ & $<0.001$ & $<0.001$ & 0.117 \\
\hline 48 & $1 \pm 1$ & $2 \pm 1$ & $2 \pm 1$ & $<0.001$ & $<0.001$ & 0.121 \\
\hline
\end{tabular}

Data are mean \pm SD. VAS, visual analogic score; TEA, thoracic epidural analgesia; MOR, intravenous morphine PCA; OXY, intravenous oxycodone PCA; SD, standard deviation; PCA, patient-controlled analgesia.

OXY (24.6 \pm 3.9 vs. $\left.27.4 \pm 3.3 \mathrm{~kg} / \mathrm{m}^{2}, \mathrm{P}<0.05\right)$. Systemic arterial pressure was lower in TEA compared to the other two intravenous analgesia groups; but was similar between MOR and OXY groups (Table 2). Pain control was better achieved in the TEA, compared to the OXY and the MOR group (Tables 3,4). It is important to notice that at all-time points, 
Table 4 Pain intensity at movement by using PHHS in preselected time points

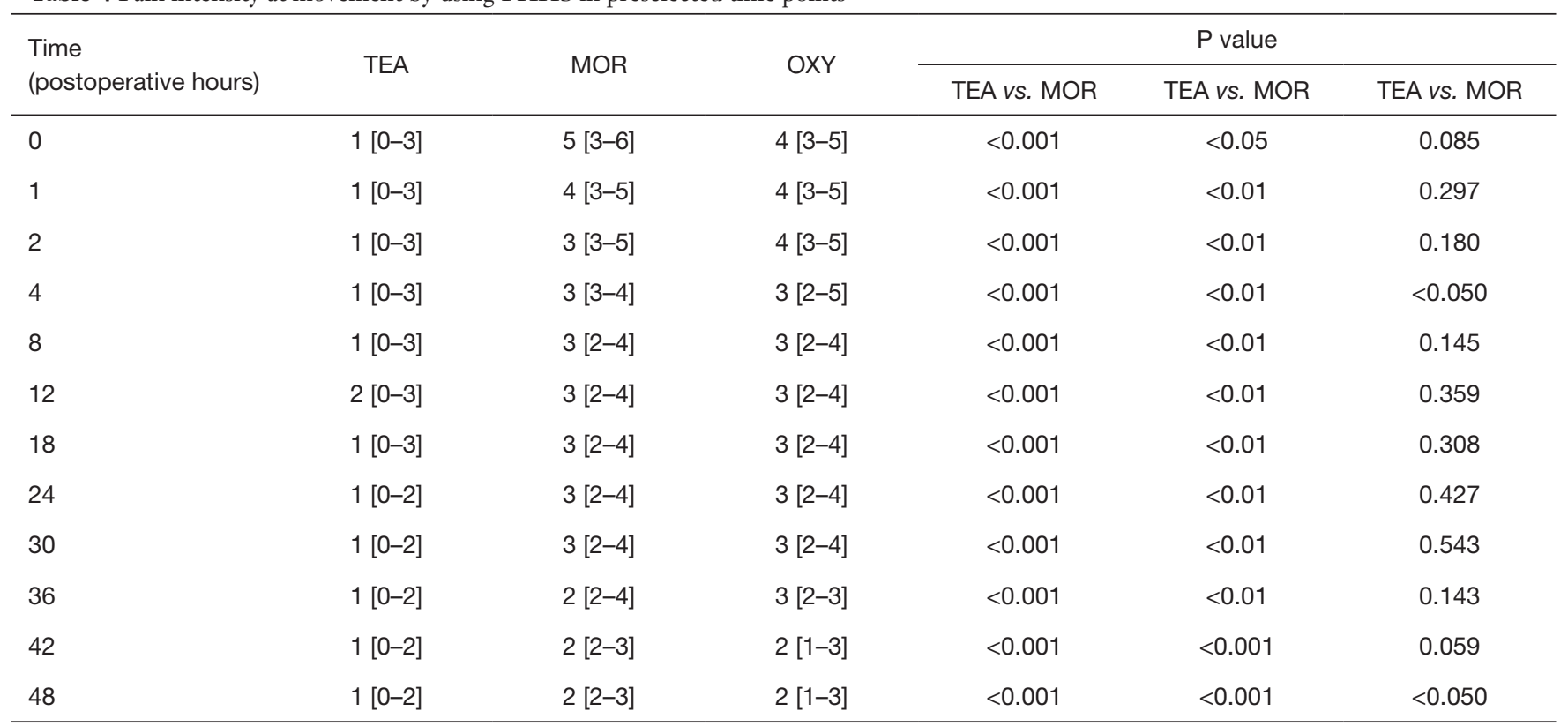

Data are mean \pm SD. PHHS, Prince Henry Hospital Score; TEA, thoracic epidural analgesia; MOR, intravenous morphine PCA; OXY, intravenous oxycodone PCA; SD, standard deviation; PCA, patient-controlled analgesia.

depth of sedation (Figure 1) and analgesia rescue (Figure 2) were higher in the MOR group than in the other 2 groups $(\mathrm{P}<0.05)$. In terms of patient satisfaction, TEA had higher rate (5 points) than intravenous PCA analgesia groups (4 points in the Likert scale) $\left(\chi^{2}=15.8 ; \mathrm{P}<0.01\right.$; Table 5).

\section{Discussion}

The main findings of our study are: (I) TEA was associated with a higher incidence of hypotension, but it provides a better analgesic control at both rest and movement, with lower sedation and higher patient satisfaction; (II) compared to morphine, oxycodone induces less hypotension and achieves better analgesic control at hour 4 and 48 with less sedation and opioid related adverse events.

Hypotension and bradycardia are common complications after central blockades. According to Carpenter et al. (23), the risk factors include high level of epidural blockade (T5 and above) and age (over 40 years old). Fanelli et al. (24), added ASA status II or above to the risk factors of hypotension and bradycardia. As previously reported (7,23-26), we observed TEA with local anesthetic infusion was associated with significantly lower systolic blood pressure than the intravenous analgesia groups. However, there was no such effect between OXY and MOR group. Similar results are described by Gaszyński et al. (27), who found no significant difference on impact on systolic blood pressure between patients receiving oxycodone and morphine for postoperative analgesia after gastrectomy (27). Analysis of changes in blood pressure in time revealed that from 2 hours of observation, patients in OXY group had significantly lower blood pressure values than baseline. This finding is not supported by any other reports and it needs further investigation on a larger study population. Analysis of diastolic blood pressure values also revealed significantly lower values at started time in TEA group compared to MOR and OXY group. There were no differences between MOR and OXY group. Contrary to previous study (13), which described significantly lower values of mean blood pressure in patients receiving morphine after abdominal surgery; we are compatible with Gaszyński et al. (27), who reported no difference in diastolic blood pressure between patients receiving morphine and oxycodone. Analysis of heart rate changes did not reveal any differences between the groups. These results are in concordance with previous reports $(27,28)$. However, we first reported a significant rise in heart rate beginning from 24 hours of observation in TEA and OXY group, which can be explained by a significantly lower level of sedation in those groups which can transfer to a higher physical activity of patients. 


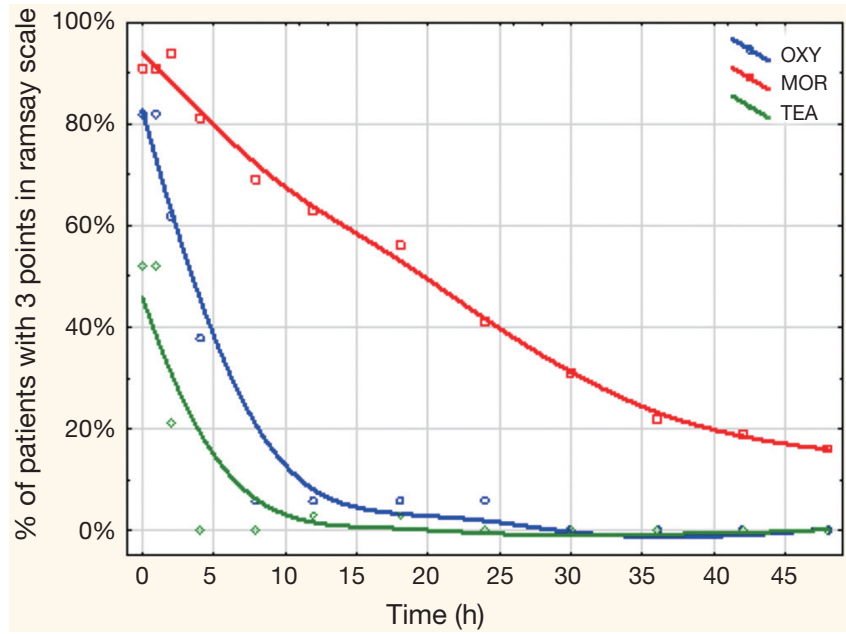

Figure 1 Regression analysis. Patients scoring 3 points in Ramsay scale in observation period between study groups. Patients who received MOR (red color) showed higher sedation levels than patients in treatment with OXY (blue color) or TEA (green color). PCA, patient-controlled analgesia; TEA, thoracic epidural analgesia; MOR, intravenous morphine PCA; OXY, intravenous oxycodone PCA.

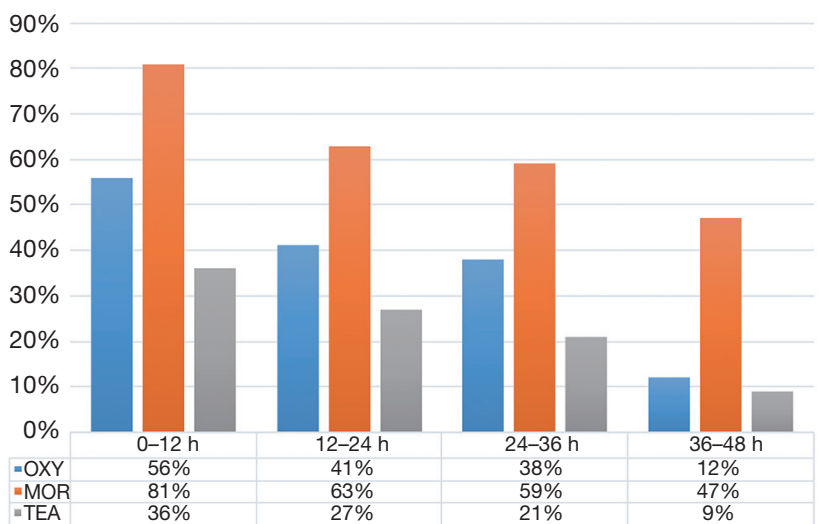

Figure 2 Rescue analgesia in time frames between study groups. These are the percentages of patients who required rescue OXY (blue color), MOR (red color) and TEA (green color) during the postoperative period. Patients in morphine group have significantly higher need of rescue analgesia than patients in the other both groups. PCA, patient-controlled analgesia; TEA, thoracic epidural analgesia; MOR, intravenous morphine PCA; OXY, intravenous oxycodone PCA.

Table 5 Odds ratio for rescue analgesia in time frames between the groups

\begin{tabular}{lllllcr}
\hline Time & TEA vs. MOR & P value & TEA vs. OXY & P value & MF vs. OXY & P value \\
\hline $0-12$ & $7.6(2.4-24.2)$ & $<0.001$ & $2.2(0.8-6.0)$ & 0.111 & $3.4(1.0-2.0)$ & $2.4(0.9-6.4)$ \\
$12-24$ & $4.4(1.5-12.9)$ & $<0.010$ & $1.9(0.7-5.3)$ & 0.233 & 0.050 & 0.093 \\
$24-36$ & $5.4(1.8-16.5)$ & $<0.010$ & $2.3(0.8-6.9)$ & 0.132 & 0.138 & $(0.9-6.3)$ \\
$36-48$ & $8.8(2.2-35.9)$ & $<0.010$ & $1.33(0.3-6.7)$ & 0.721 & $6.6(1.9-23.2)$ & $<0.010$ \\
\hline
\end{tabular}

Data expressed as odds ratio (CI 95\%). Time, points of postoperative measurements (in hours). $\mathrm{Cl}$, confidence intervals; TEA, thoracic epidural analgesia; MOR, intravenous morphine PCA; OXY, intravenous oxycodone PCA; MF, morphine; PCA, patient-controlled analgesia.

To conclude it is important to state that there were no incidents of hypotension below $90 \mathrm{mmHg}$ systolic blood pressure (SBP) or bradycardia. The most stable influence on circulatory system was observed in MF group. It can be credited to the highest sedation level in this

Epidural analgesia is still considered a gold standard in treating pain after thoracic procedures $(8,29)$. In many studies and systematic reviews there are evidence of superiority of this technique compared to other methods of relieving acute postoperative pain $(8,11,30)$. Moreover, some of those papers state that the quality of life of the patients that were treated with epidural analgesia (30). Our study also supports this thesis TEA with bupivacaine and fentanyl significantly decreased pain levels at rest and movement (by using VAS and PHHPS, respectively) compared to PCA delivered systemic opioid analgesia. Difference in outcome is probably associated with a different patient population and kind of surgery.

Our data analysis did not reveal any difference in pain intensity at rest (VAS) between patients treated with morphine and oxycodone. Similar results are previously described in neurosurgery (31), and in abdominal surgery $(11,12,32)$.

Introducing early postoperative physiotherapy is crucial for avoiding serious respiratory complications after thoracic surgery $(5,33)$, but it also increases the intensity of 
postoperative pain. We showed, TEA was more effective in controlling pain during physiotherapy than both intravenous analgesia groups; but we didn't find any clinical significant difference between morphine and oxycodone groups which demonstrate similar antinociceptive potency of those substances.

Excessive sedation is one of the most common adverse events occurring during systemic opioid therapy (34). It is particularly dangerous in thoracic patient population because it increases the risk of developing serious respiratory complications like respiratory depression, sputum retention and infection $(5,8,33)$. In our study, patients in TEA and OXY group showed significantly lower sedation than those MOR groups, without significant differences between TEA and OXY groups. Our results are opposite to other studies $(12,31,35)$, which found no differences in sedation between patients receiving epidural bupivacaine $v s$. systemic morphine (35), and neither between systemic morphine (31), fentanyl (12) and remifentanil (36) vs. oxycodone. However, they are supported by pharmacokinetics of oxycodone which is metabolized without any active derivatives that could augment sedation (37).

Effective pain management must also include breakthrough pain treatment. This kind of pain is not only unpleasant for the patient but it also requires more involvement form the medical staff and is difficult to alleviate. This is the reason why we should choose drugs with the lowest risk of breakthrough pain occurrence. Our data showed significant decrease in the necessity of a rescue drug in TEA and OXY groups but we found no differences in distribution of rescue analgesia in all three study groups. In addition, we observed that using morphine is connected with a significantly higher probability of needing rescue analgesia compared to oxycodone or epidural analgesia (6 and 8 times higher respectively). These findings were previously reported: (I) epidural analgesia is associated with lower need of rescue analgesia (38); (II) opioid drugs have different need of rescue analgesia (28); and (III) oxycodone has longer duration in nociceptive effect than morphine (13). This phenomenon can be attributed to a high concentration of a free fraction of oxycodone in cerebrospinal fluidit is 6 times higher than morphine with comparable blood concentration. Easy penetration of blood-brain barrier makes an analgesic potential of oxycodone higher that of morphine $(10,39,40)$.

Regarding pain management safety, opioid-related adverse effects, we found no significant difference between the groups 48 postoperative hours. This is similar to the results presented by other authors $(12,28,31,41,42)$, who investigated adverse events associated with oxycodone and morphine use and conclude similarity in adverse events profile of both. In terms of patient satisfaction, by using Likert scale (22), we found patients in TEA group were the most satisfied with their pain treatment compared to OXY and MOR group. This is consistent with Cassady et al. (32) but not with Ali et al. (30) who found similar satisfaction with epidural compared to intravenous opioid analgesia.

\section{Conclusions}

In our study TEA is the most effective analgesic technique in postoperative pain management after anterolateral thoracotomy, Efficacy of intravenous morphine and oxycodone PCA is similar but there is higher level of sedation and probability of needing additional rescue analgesia when using morphine compared to oxycodone PCA. Finally, patient satisfaction is better with TEA, with no differences between morphine and oxycodone groups.

\section{Acknowledgements}

None.

\section{Footnote}

Conflicts of Interest: The authors have no conflicts of interest to declare.

Ethical Statement: The study was approved by the Institutional Review Board (KNW/0022/KB1/23/13) and written informed consent was obtained from the patients.

\section{References}

1. Mesbah A, Yeung J, Gao F. Pain after thoracotomy. BJA Educ 2016;16:1-7.

2. Sharrock NE, Cazan MG, Hargett MJ, et al. Changes in mortality after total hip and knee arthroplasty over a tenyear period. Anesth Analg 1995;80:242-8.

3. Katz J, Jackson M, Kavanagh BP, et al. Acute pain after thoracic surgery predicts long-term post-thoracotomy pain. Clin J Pain 1996;12:50-5.

4. Niraj G, Kelkar A, Kaushik V, et al. Audit of postoperative pain management after open thoracotomy and the incidence of chronic postthoracotomy pain in more than 500 patients at a tertiary center. J Clin Anesth 
2017;36:174-7.

5. Elmore B, Nguyen V, Blank R, et al. Pain Management Following Thoracic Surgery. Thorac Surg Clin 2015;25:393-409.

6. Rodriguez-Aldrete D, Candiotti KA, Janakiraman R, et al. Trends and New Evidence in the Management of Acute and Chronic Post-Thoracotomy Pain-An Overview of the Literature from 2005 to 2015. J Cardiothorac Vasc Anesth 2016;30:762-72.

7. Yeung JH, Gates S, Naidu BV, et al. Paravertebral block versus thoracic epidural for patients undergoing thoracotomy. Cochrane Database Syst Rev 2016;2:CD009121.

8. Rawal N. Current issues in postoperative pain management. Eur J Anaesthesiol 2016;33:160-71.

9. Aubrun F, Monsel S, Langeron O, et al. Postoperative titration of intravenous morphine. Eur J Anaesthesiol 2001;18:159-65.

10. Blumenthal S, Min K, Marquardt M, et al. Postoperative intravenous morphine consumption, pain scores, and side effects with perioperative oral controlled-release oxycodone after lumbar discectomy. Anesth Analg 2007;105:233-7.

11. Joshi GP, Bonnet F, Shah R, et al. A systematic review of randomized trials evaluating regional techniques for postthoracotomy analgesia. Anesth Analg 2008;107:1026-40.

12. Hwang BY, Kwon JY, Kim E, et al. Oxycodone vs. fentanyl patient-controlled analgesia after laparoscopic cholecystectomy. Int J Med Sci 2014;11:658-62.

13. Kalso E, Pöyhiä R, Onnela P, et al. Intravenous morphine and oxycodone for pain after abdominal surgery. Acta Anaesthesiol Scand 1991;35:642-6.

14. Wang J, Ma H, Zhou H, et al. Effect of preoperative intravenous oxycodone administration on sufentanil consumption after retroperitoneal laparoscopic nephrectomy. Anaesthesiol Intensive Ther 2016;48:300-4.

15. Staahl C, Dimcevski G, Andersen SD, et al. Differential effect of opioids in patients with chronic pancreatitis: an experimental pain study. Scand J Gastroenterol 2007;42:383-90.

16. Huskisson EC. Measurement of pain. Lancet 1974;2:1127-31.

17. Kawahara R, Tamai Y, Yamasaki K, et al. The analgesic efficacy of ultrasound-guided transversus abdominis plane block with mid-axillary approach after gynecologic laparoscopic surgery: A randomized controlled trial. J Anaesthesiol Clin Pharmacol 2015;31:67-71.
18. Ramsay MA, Savege TM, Simpson BR, et al. Controlled sedation with alphaxalone-alphadolone. Br Med J 1974;2:656-9.

19. Apfelbaum JL, Gan TJ, Zhao S, et al. Reliability and validity of the perioperative opioid-related symptom distress scale. Anesth Analg 2004;99:699-709.

20. Chan KS, Chen WH, Gan TJ, et al. Development and validation of a composite score based on clinically meaningful events for the opioid-related symptom distress scale. Qual Life Res 2009;18:1331-40.

21. Yadeau JT, Liu SS, Rade MC, et al. Performance characteristics and validation of the Opioid-Related Symptom Distress Scale for evaluation of analgesic side effects after orthopedic surgery. Anesth Analg 2011;113:369-77.

22. Harland NJ, Dawkin MJ, Martin D. Relative utility of a visual analogue scale vs. a six-point Likert scale in the measurement of global subject outcome in patients with low back pain receiving physiotherapy. Physiotherapy 2015;101:50-4.

23. Carpenter RL, Caplan RA, Brown DL, et al. Incidence and risk factors for side effects of spinal anesthesia. Anesthesiology 1992;76:906-16.

24. Fanelli G, Casati A, Berti M, et al. Incidence of hypotension and bradycardia during integrated epidural/ general anaesthesia. An epidemiologic observational study on 1200 consecutive patients. Italian Study Group on Integrated Anaesthesia. Minerva Anestesiol 1998;64:313-9.

25. Fikkers BG, Damen J, Scheffer GJ, et al. Thoracic epidural analgesia and antihypertensive therapy: a matter of timing? Eur J Anaesthesiol 2006;23:893-5.

26. Holte K, Foss NB, Svensen C, et al. Epidural anesthesia, hypotension, and changes in intravascular volume. Anesthesiology 2004;100:281-6.

27. Gaszyński T. The comparison study of oxycodone and morphine for postoperative analgesia in morbidly obese patients. Anestezjologia i Ratownictwo 2014;8:292-8.

28. Turktan $M$, Unlugenc $H$, Gulec E, et al. Coadministration of intravenous remifentanil and morphine for postthoracotomy pain: comparison with intravenous morphine alone. J Cardiothorac Vasc Anesth 2015;29:133-8.

29. Misiołek H, Cettler M, Woroń J, et al. The 2014 guidelines for post-operative pain management. Anaesthesiol Intensive Ther 2014;46:221-44.

30. Ali M, Winter DC, Hanly AM, et al. Prospective, randomized, controlled trial of thoracic epidural or patient-controlled opiate analgesia on perioperative quality of life. Br J Anaesth 2010;104:292-7. 
31. Silvasti M, Rosenberg P, Seppälä T, et al. Comparison of analgesic efficacy of oxycodone and morphine in postoperative intravenous patient-controlled analgesia. Acta Anaesthesiol Scand 1998;42:576-80.

32. Cassady JF Jr, Lederhaas G, Cancel DD, et al. A randomized comparison of the effects of continuous thoracic epidural analgesia and intravenous patientcontrolled analgesia after posterior spinal fusion in adolescents. Reg Anesth Pain Med 2000;25:246-53.

33. Agostini P, Cieslik H, Rathinam S, et al. Postoperative pulmonary complications following thoracic surgery: are there any modifiable risk factors? Thorax 2010;65:815-8.

34. Larsen R. Anestezjologia. Wrocław: Urban and Partner, 2013.

35. Mercanoğlu E, Alanoğlu Z, Ekmekçi P, et al. Comparison of intravenous morphine, epidural morphine with/without bupivacaine or ropivacaine in postthoracotomy pain management with patient controlled analgesia technique. Braz J Anesthesiol 2013;63:213-9.

36. Kucukemre F, Kunt N, Kaygusuz K, et al. Remifentanil compared with morphine for postoperative patientcontrolled analgesia after major abdominal surgery: a randomized controlled trial. Eur J Anaesthesiol 2005;22:378-85.

Cite this article as: Bialka S, Copik M, Daszkiewicz A, Rivas E, Ruetzler K, Szarpak L, Misiolek H. Comparison of different methods of postoperative analgesia after thoracotomy-a randomized controlled trial. J Thorac Dis 2018;10(8):48744882. doi: $10.21037 / j t d .2018 .07 .88$
37. Lalovic B, Kharasch E, Hoffer C, et al. Pharmacokinetics and pharmacodynamics of oral oxycodone in healthy human subjects: role of circulating active metabolites. Clin Pharmacol Ther 2006;79:461-79.

38. Webb AR, Leong S, Myles PS, et al. The addition of a tramadol infusion to morphine patient-controlled analgesia after abdominal surgery: a double-blinded, placebocontrolled randomized trial. Anesth Analg 2002;95:1713-8.

39. Boström E, Hammarlund-Udenaes M, Simonsson US. Blood-brain barrier transport helps to explain discrepancies in in vivo potency between oxycodone and morphine. Anesthesiology 2008;108:495-505.

40. Sacerdote P, Manfredi B, Mantegazza P, et al. Antinociceptive and immunosuppressive effects of opiate drugs: a structure-related activity study. Br J Pharmacol 1997;121:834-40.

41. Unlugenc H, Tetiker S, Isik G. Addition of remifentanil to patient-controlled tramadol for postoperative analgesia: a double-blind, controlled, randomized trial after major abdominal surgery. Eur J Anaesthesiol 2008;25:968-75.

42. Park JH, Lee C, Shin Y, et al. Comparison of oxycodone and fentanyl for postoperative patient-controlled analgesia after laparoscopic gynecological surgery. Korean J Anesthesiol 2015;68:153-8. 